\title{
Carbon fiber: Not just for your mountain bike anymore
}

\author{
Benjamin Wei, MD
}

\author{
From the Division of Cardiothoracic Surgery, Department of Surgery, University of Alabama Birmingham School \\ of Medicine, Birmingham, Ala. \\ Disclosures: Author has nothing to disclose with regard to commercial support. \\ Received for publication June 1, 2018; revisions received June 1, 2018; accepted for publication June 1, 2018; \\ available ahead of print July 27, 2018 \\ Address for reprints: Benjamin Wei, MD, Division of Cardiothoracic Surgery, Department of Surgery, University \\ of Alabama Birmingham School of Medicine, ZRB 707, 1720 2nd Ave S, Birmingham, AL 35294-0007 \\ (E-mail: bwei@uab.edu) \\ J Thorac Cardiovasc Surg 2018;156:e181-2 \\ 0022-5223/\$0.00 \\ Published by Elsevier Inc. on behalf of The American Association for Thoracic Surgery \\ https://doi.org/10.1016/j.jtcvs.2018.06.027
}

Reconstruction after chest wall resection has been performed in a number of different ways in the past, depending on the nature and size of the defect. Autologous tissue flaps are useful when extensive skin and soft tissue has been resected in addition to the ribs. More commonly, the use of synthetic or biologic mesh has been considered sufficient when the chest wall defect is limited to ribs or sternum, with a low risk of complications when used in noninfected settings. ${ }^{1}$ For certain applications, especially sternal reconstruction, practitioners have reinforced mesh with such materials as methyl methacrylate to create a rigid structure that is more protective when impact is sustained. ${ }^{2}$ The use of methyl methacrylate for reconstruction of resected ribs is less common, because this area of the chest wall exhibits more motion during breathing, which can lead to a flail situation and discomfort. Furthermore, rigid reconstruction is not thought to be necessary; nonrigid mesh reconstruction appears to mitigate some of the impairment in respiratory mechanics after chest wall resection, as measured by pulmonary function testing parameters such as forced expiratory volume in 1 second, forced vital capacity, and diffusing capacity of lung for carbon monoxide. ${ }^{3}$

Even so, practitioners continue to seek more faithful replicas of resected chest wall. Wang and colleagues ${ }^{4}$ in their case report in this issue of the Journal, "Chest Wall Reconstruction with 3-Dimensional Custom-made Carbon-Fiber Ribs," demonstrate the state of the art when it comes to chest wall reconstruction. They used a 3-dimensional model of the chest skeleton to create a custom carbon-fiber implant for reconstruction of a large defect created after resection of a $22 \times 20 \times 18$-cm chondrosarcoma. Others have created synthetic ribs with 3-dimensional printing with titanium and porous polytethylene. ${ }^{5,6}$ Wang and colleagues ${ }^{4}$ cite the advantages of using carbon fiber rather than metal: less interference if postoperative radiotherapy becomes necessary and less artifact when performing surveillance computed tomographic scans. One interesting aspect of using carbon fiber is that the elasticity of the neorib can be adjusted to mimic the quality of biologic ribs by controlling

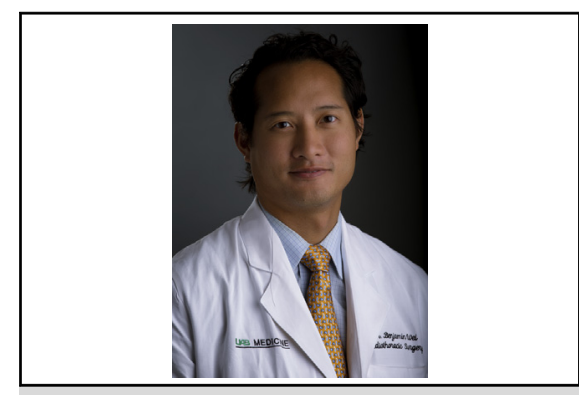

Benjamin Wei, MD

Central Message

Before we as a field move on from the tried and true to new, more expensive ways to solve the problem of chest wall reconstruction, we should consider whether it is worth the leap.

See Article page e177.

how much carbon is deposited during the printing process. Although such surgical artistry is impressive, Wang and colleagues ${ }^{4}$ do not cite the cost of such advanced technology, nor do we know whether such a technique has any measurable benefit to the patient. Indeed, a premade rib fixation device that is almost certainly less expensive exists and has shown promise for chest wall reconstruction. ${ }^{7,8}$ The larger question, however, of whether rigid reconstruction of the chest wall affects pulmonary function, pain and recovery, surveillance imaging, or cosmesis relative to nonrigid reconstruction remains unanswered. Before we as a field move on from the tried and true to new, more expensive ways to solve an age-old problem, we should consider whether it is worth the leap.

\section{References}

1. Deschamps C, Tirnaksiz BM, Darbandi R, Trastek VF, Allen MS, Miller DL, et al Early and long-term results of prosthetic chest wall reconstruction. $J$ Thorac Cardiovasc Surg. 1999;117:588-91; discussion 591-2.

2. Walsh GL, Davis BM, Swisher SG, Vaporciyan AA, Smythe WR, WillisMerriman K, et al. A single-institutional, multidisciplinary approach to primary sarcomas involving the chest wall requiring full-thickness resections. J Thorac Cardiovasc Surg. 2001;121:48-60.

3. Leuzzi G, Nachira D, Cesario A, Novellis P, Petracca Ciavarella L, Lococo F, et al Chest wall tumors and prosthetic reconstruction: a comparative analysis on functional outcome. Thorac Cancer. 2015;6:247-54.

4. Wang B, Mei X, Liu W, Yu F. Chest wall reconstruction with 3-dimensional custom-made carbon fiber ribs. J Thorac Cardiovasc Surg. 2018;156:e177-9.

5. Oswald N, Senanayake E, Naidu B, Khalil H, Bishay E. Chest wall mechanics in vivo with a new custom-made three-dimensional-printed sternal prosthesis. Ann Thorac Surg. 2018;105:1272-6.

6. Aranda JL, Jiménez MF, Rodríguez M, Varela G. Tridimensional titanium-printed custom-made prosthesis for sternocostal reconstruction. Eur J Cardiothorac Surg. 2015;48:e92-4. 
7. Fabre D, El Batti S, Singhal S, Mercier O, Mussot S, Fadel E, et al. A paradigm shift for sternal reconstruction using a novel titanium rib bridge system following oncological resections. Eur J Cardiothorac Surg. 2012;42:965-70.
8. Gonfiotti A, Santini PF, Campanacci D, Innocenti M, Ferrarello S, Janni A, et al. Use of moldable titanium bars and rib clips for total sternal replacement: a new composite technique. J Thorac Cardiovasc. 2009;138:1248-50. 